\title{
Tourism Development and Planning at a Local Authority Level: A Case in Manjung, Perak, Malaysia
}

\author{
Nor Hasliza Md Saad ${ }^{1}$, Siti Nabiha Abdul Khalid ${ }^{2}$, Norliza Zainol Abidin ${ }^{3}$ \\ ${ }^{1}$ School of Management, Universiti Sains Malaysia, 11800 Penang, Malaysia \\ ${ }^{2,3}$ Graduate School of Business, Universiti Sains Malaysia, 11800 Penang, Malaysia
}

\begin{abstract}
Due to the importance of the tourism industry in the country, it is crucial to ensure that local authorities in Malaysia implement sustainable tourism development. In the $10^{\text {th }}$ Malaysian Plan, the government set a key target to be achieved for the tourism sector. One of the key parties responsible for ensuring that the set targets are achieved is the local authorities, who are responsible for providing proper maintenance because the tourism destinations fall under their area of jurisdiction. The aim of this article is to explore tourism development and planning in one of the popular tourism destination and to analyse the role that local authorities play in the development process. This paper explores the local authorities' views and opinions on their tourism development area using interview and focus group approaches. The paper also combines the analysis of government policy and planning documents with a review of tourism development literature. The findings reveal challenges and issues that are experienced by the local authorities in regard to setting the direction, development and management of tourism development. The issues of tourism development are then discussed for the government to ensure tourism development sustainability in the long term.
\end{abstract}

\section{Introduction}

Over the past decade, a number of countries around the world have considered the tourism industry to be one of the most important contributions to their economic and social development. In recent years, the tourism industry has been one of the world's largest industries and generated approximately 5 percent of world GDP in 2011, 9 percent of world GDP in 2012 and 12 percent of world GDP in 2013 [1]. According to Ibrahim and Ahmad [2], tourism planning is a process of managing and coordinating the tourism area to suggest the best approach that can lead to the success of and satisfaction with tourism.

Malaysia considers the tourism industry important because it has been identified as a driver of economic activity and social development. The government has played an important role in stimulating the development of the tourism industry. In the $10^{\text {th }}$ Malaysian Plan, significant attention was given to the tourism sector to improve Malaysia's position in this sector, so it could be the top 10 in terms of global tourism receipts, and to increase the sector's contribution by 2.1 times, which would contribute RM115 billion in receipts and provide two million jobs in this industry in 2015 [3]. 
Awareness of the important concept of sustainable tourism development has been incorporated into national planning. The purpose of this paper is to provide insight into sustainable tourism development within the national planning process.

In response to the importance of the tourism industry, governments are increasingly anticipating the active role of the local authorities in the planning, management and promotion of tourism in their respective areas [4]. Though the traditional role of the local authorities has been to provide and maintain public facilities, the role of the local authorities in tourism planning is to manage certain issues related to enhancing tourism activities.

Consistent with this role, the aim of this article is to explore tourism development and planning in one of the popular tourism destination and to analyse the role that the local authorities play in the development process. This paper explores the local authorities' views and opinions regarding the tourism development area in the Manjung District of Perak, Malaysia.

\section{Role of Local Authorities in Tourism Sector}

In Malaysia, the government is responsible for the change of policies and strategies and for developing policies that are consistent with the country's development in promoting growth in the tourism sector. The government is responsible for preparing development plans for both the short and the long terms, identifying potential locations for tourism and regulating the development of a more systematic approach to tourism. Malaysia is a federal country in which the Federal Constitution is the supreme law. All of the laws and governmental sovereignty are subject to the Federal Constitution. The federal system contains three forms of government structure: the Federal Government, the State Government and the Local Government (Ministry of the Welfare of the City, Housing and the Local Government, 2011), as shown in Figure 1.

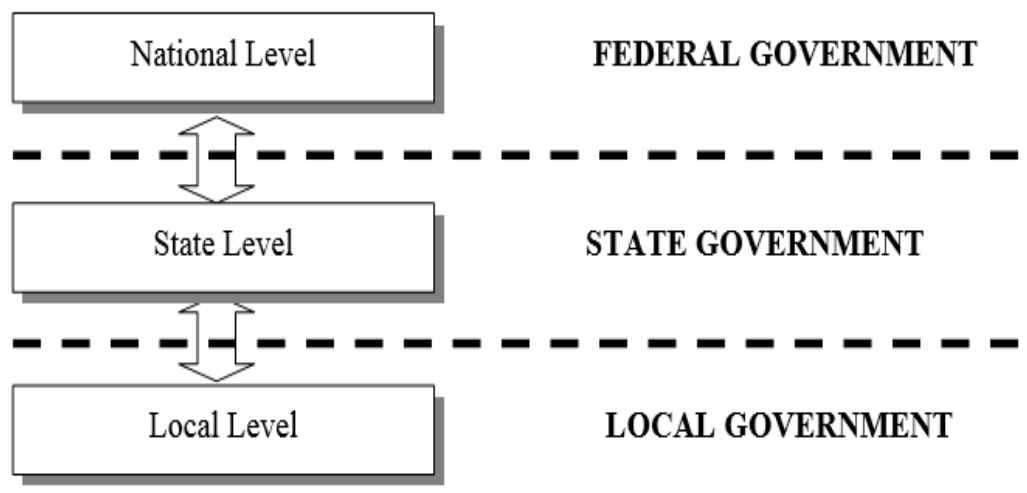

Figure 1. Malaysian Administrative Structure

Currently, the total number of local authorities across the country is 149 . Their main task relates to the development and use of land in their respective areas. The duties of the local planning authorities are as follows:

a. to regulate, control and plan the development and use of all of the land and buildings in the area;

b. to undertake, assist and promote the collection, maintenance and publication of statistics, bulletins, monographs and other aspects that are related to town and country planning

c. to perform any other duties that are assigned to them by the Authority of the State or the State Planning Committee. 


\section{Research Methodology}

The research method used for the study is the case study. This method well suited to an exploratory study to get deep understanding of surrounding situation. The case and the unit of analysis for this study is the Manjung Municipal Council. . A case study protocol was developed to guide the case study processes by identifying the relevant questions to be gathered.

The use of such a protocol can further strengthen study reliability. The protocol derives from review of the literature relating to tourism development practices in local authorities. Data collection was divided into two parts of qualitative research was conducted to obtain feedback and experiences from representative of Manjung local authority.

Part one was for the purpose of identifying the responsibly of local authority in dealing with tourism development in their area. In this stage the interview session was done in July 2013 from two representative of Manjung local authority who are responsible about tourism development. Part two was to gain a better understanding of their experience in terms of issues, challenging area and future direction of their responsibility in tourism development. Areas explored included how they plan and management their tourism area, what are the issues that come across with the tourism development, and how they deal with the challenging problems. .

In this stage, three administrative departments in the Manjung Municipal Council were invited and discussed about their overall strategy in tourism development. This is accomplished by prompting the group with pre-specified topics in the tourism development, allowing the discussion to evolve around these open-ended question. Using focus groups allows the interaction and extract insights from the participants [5-7].

\section{A Case Study of Coastal and Island Tourism Development by the Manjung Municipal Council}

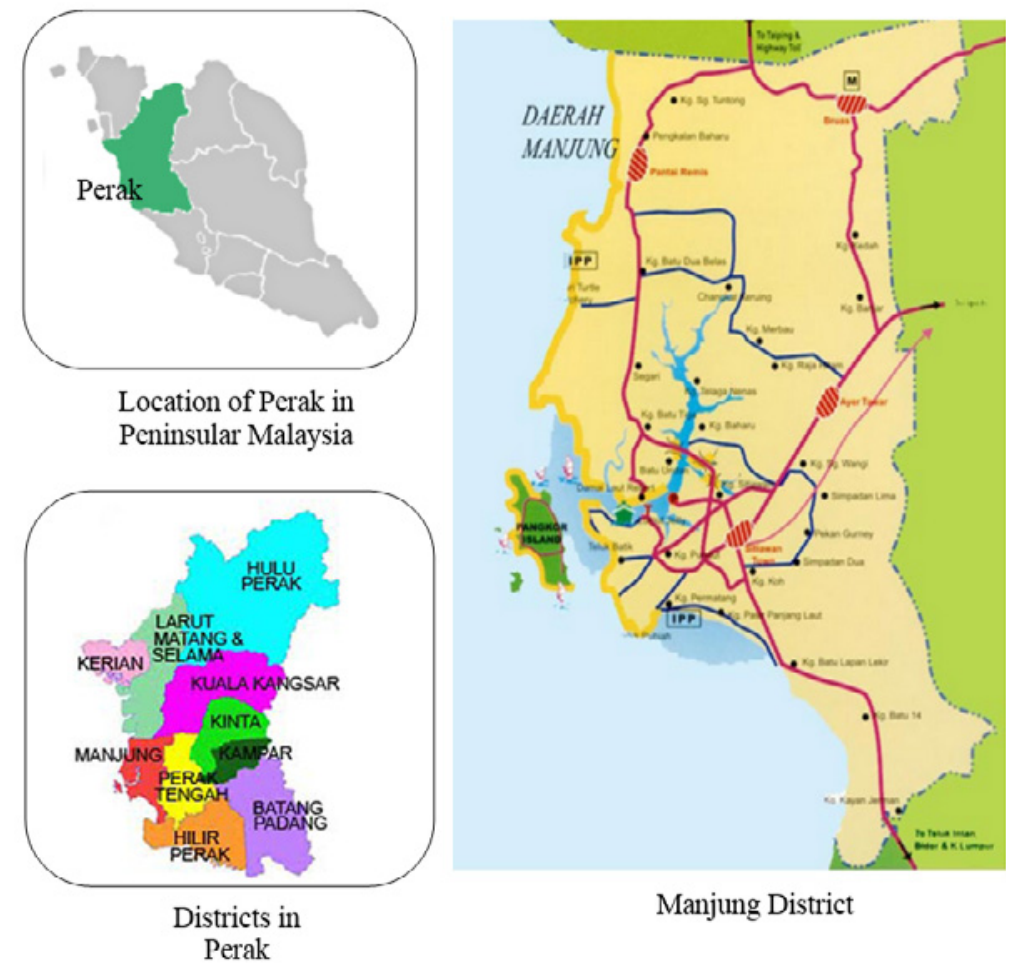

Figure 2. Location of District of Manjung. 
This case study is related to the tourism development of the island and the coastline that is under the jurisdiction of the local authorities in the Manjung Municipal Council (MMC). The district is located in Perak, as shown in Figure 2. The beauty of nature's rich beaches and islands that are ringed with coral reefs and marine life make the drive to the Manjung District a major tourist attraction for the state of Perak.

Consistent with the concept of development and the development plan, the MMC is able to fulfil the goal of developing the tourism sector in its area of administration. There are many tourist attractions in this area that can improve the economy and safeguard the income of local residents. However, the local authorities also face issues and challenges in developing the MMC's role in the tourism sector.

\subsection{Background Manjung Municipal Council (MMC) Local Authority}

The Manjung Municipal Council (MMC) is one of the local authorities that has the status of a municipality and is located in the State of Perak. Before being recognised as a municipality on 1 August 2001, it was previously known as the Manjung District Council (MDC). The Manjung District Council was established on 1 January 1980 due to the merger of several Local Government Management Boards.

Most of the Manjung District is located in the administrative area of the MMC. The major cities in the MMC area include Setiawan, Lumut, Seri Manjung, Beruas, Lekir, Pantau Remis and Pangkor Island.

\subsection{The Role of Manjung Municipal Council in Tourism Development}

The MMC plays a key role as the local authority that is responsible for the administration of the area, collecting, controlling, and planning according to the development plan. It is also responsible for the work, as contained in Act 171 of the MPM has a clear vision of tourism, that will cause "Manjung City Tourism and Maritime to be advanced, progressive, prosperous and leading by 2015", with the aim of creating comfortable urban areas that are safe and harmonious through continuous capacity building in all of its areas.

When creating the tourism sector, the MMC created special units and parts for the management and development of tourism. There are two departments/ divisions and units:

- Travel and Research Division under the Department of Community Development and Social Development

- $\quad$ Lumut Development and Management Unit

\subsection{The Development Plan for the Tourism Sector of the Manjung Municipal Council (MMC)}

When determining the plans and development for an area, a development plan is a key instrument. The MMC for local authorities adopts instruments based on a number of development plans that have been enacted by the authorities at the national, state and local sectors. Figure 3 shows the development plan that is directly involved in the direction and development of tourism by the MMC. 

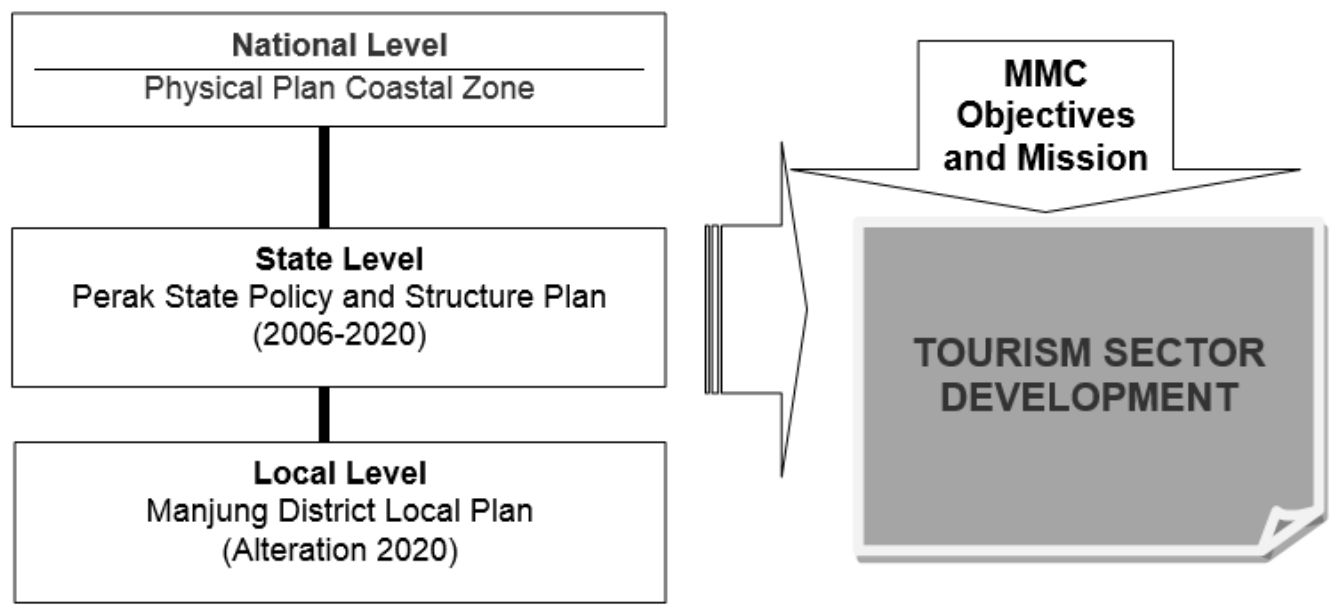

Figure 3. Location of District of Manjung.

Each plan has a content development policy and a comprehensive strategy and serves as guideline for the development of MMC.

\subsubsection{The National Physical Coastal Zone Plan (NPCZP)}

This is a national physical plan that was prepared by the Department of Town and Country Planning in Peninsular Malaysia as a guide for planning along the coastal areas in Malaysia. NPCZP also involves local authorities in MMC due to its coast and the Pangkor Island. This plan details the physical planning and physical development of the comprehensive and sustainable management and protection of coastal and island ecosystems. For the MMC, the area that is involved in the physical plan is Planning Unit 3 (PU3):

PU3: Pantai Remis (according to the A179 road that cuts straight towards the coast) - Sungai Perak (page 68, RZFPPN). According to the physical plan, the study area includes UP3 coastal ecosystems and the sandy beach of Pangkor Island (Pulau Pangkor and SEV), seaweed (in Teluk Nipah, Pangkor Island), sea turtle nesting sites (SEV) and coastal forests (SEV), which contains different species of plants and animals that are rarely found. The main responsibility of the MMC is to implement the physical plan for developing the tourism sector of the island and coastline to protect and preserve the natural resources sustainably.

\subsubsection{Perak State Policy and Structure Plan}

At the state level, development planning is more specific to the specific requirements of each state. The MMC for local authorities must consider the planning and development of policies and strategies that are outlined by the Perak State Government and the Review of the Structure of the State of Perak from 2006 to 2020.In the structure plan that was adopted, the Balanced and Integrated Development Strategy (BIDS) was used as the basis for development. The State Government identifies two main strategies:

- the Sustainable Development Strategy of the State of Perak

- the Balanced and Integrated Development Strategy (BIDS) 
The strategies that are outlined in the main strategy are clear and consistent with the main goal of the MMC, which is to make Manjung a tourist town. This strategy accounts for the divided areas of the development planning zones. The areas in the MMC are categorised in the Kinta Valley Metropolitan Planning Zone. This zone includes the main focus areas of development, particularly the development of residential, municipal, industrial and tourism sectors.

\subsubsection{Manjung District Local Plan}

A development plan at the local level, which is known as the Manjung District Local Plan (Alteration) 2020, was gazetted on 4 August 2011 and includes overall of Manjung District. The requirements of Manjung District Local Plan (Alteration) 2020 are to coordinate four existing local plan reports:

i.Local Plan Lumut-Seri Manjung 1999-2010

ii.Local Plan Sitiawan-Ayer Tawar 1999-2010

iii.Local Plan Pulau Pangkor 1999-2015

iv.Local Plan Manjung 2002-2015

The local plan must also translate the development policies and strategies that had identified in the Kinta Valley Metropolitan Planning Zone of the Manjung District. At the same time, the needs of the local plan are adopted into the current policy at the national level, as shown in the national physical planning and economic development in the corridor region. The local plan contains details of a comprehensive plan that allows the development in MPM to be controlled effectively. The contents of this document are consistent with the goals and the vision of the MPM, which focus on making tourism a major development in the Manjung District. The strategies that are consistent with the development of tourism include the following:

- the Economic development strategy

- the Social development strategy

- the Physical and environmental development strategy

- the Pangkor Socio-Economic Development Strategy

The strategies discussed above were developed based on the issues of potential development that have been identified. They will also help the MMC provide guidelines for monitoring and a planning framework that focuses more specifically on development. Separate from this strategy, development concepts that include more detail, clarity and focus are also included in the local plan. Concept development is intended to ensure balanced development between urban and rural areas. This is known as the concept of integration and focus. This concept is divided into three zones of physical planning, which aim to ensure a balanced development between urban and rural areas. The physical planning zones are as follows:

- Physical planning zone of the island - a focus on Pangkor Island, Pangkor Laut and Pulau Gagasan Sembilan.

- Physical planning zone of coastal and river areas - along the walls up to the Jambatan Tuanku Permaisuri.

- Physical planning zone of land - covering the Central Region of Semi Lumut, Seri Manjung, and Sitiawan-Ayer Tawar.

Concept development and the integration of this focus is supported by comprehensive infrastructure systems to boost development. Improved road communication systems are a part of this focus, particularly in remote areas and rural growth centres. Overall tourism development in the area of MMC is considered to be consistent with development at the national, state and local levels. However, local authorities also are credited with the goal and vision to make the city centre of Manjung a leader in municipal tourism by 2015 . 


\subsection{Issues and Challenges of Island and Coastal Tourism in the Manjung Municipal Council (MMC)}

In addition, there are a range of issues and challenges regarding sustainable tourism development in relation to the Manjung township's vision. The issues and challenges that are faced include the following:

- There is a lack of development funds. Funds that are dedicated to tourism development are required to develop a tourism product. For example, there is no provision for promoting the development of tourism on the island of Giam. Funds are required for developing the old city and river tourism attractions. There is also no provision of funds for developing a water taxi that can take visitors to activities on the river walls or for developing the old town in Pangkor Island and Beruas.

- Weaknesses in tourism infrastructure are observed in the tourist destination area in Manjung District. Highway development from Teluk Batik to Teluk Rubiah should be created because it would make a huge impact on the development of tourism products, particularly in small economies.

- Overlaps occur between the operations of the local government areas in regard to tourist destinations. Overlaps in the area of operations are also a challenge faced in the development of tourism in the MMC. For example, Pantai Teluk Senangin is not within the area of operations according to the Manjung Municipal Council. Additionally, tourist destinations in Beruas (Air Terjun Ulu Licin) are included in the operations of local governments because the location of the entrance to the area is under the Manjung District; however, the area that is under the waterfall in Kuala Kangsar is outside this area.

- There is a lack of activities in the tourist attractions, which is included in the area of operations. Annual activities to attract tourists, especially domestic tourists, are needed and have been created in Pulau Pangkor and Lumut.

- Infrastructure problems - There are infrastructure problems that need to be improved, such as the lack of road signs on the main road to the tourism product and problems of an inadequate electricity supply in the tourism areas.

- There is a shortage of skilled workers who are involved in the tourism industry. Skilled human resources in the tourism industry, particularly boat operators and operators of similar sports in Pangkor Island, Teluk Batik, need to be improved through training.

\section{Conclusion}

The MMC in Perak is a tourist destination that has numerous attractions. It has the huge responsibility of ensuring that their efforts are effective and that they continue to be committed to the success of the tourism sector. Although many of the challenges have been described, MMC has identified actions that need to be implemented to achieve its mission of making Manjung City tourism superior in Malaysia. It is evident that the success of tourism activities requires the close cooperation of various stakeholders, such as the government, the tourism industry and local residents. The importance of planning and management of the tourism sector is very clear and also an important role in ensuring that this development goes according to requirements and established plan. There are a variety of tourism-related development plan in place to ensure that all development in accordance with the criteria and that would meet the needs of sustainable development. . It is clear that tourism planning and development in Malaysia applies the traditional top-down approach, which starts with national goals and attempts to have them implemented at the local level. It shows that the planning undertaken by the government is very rigorous and detailed and balanced to ensure that the physical, social and economic upliftment of life, generate income, contribute to the economy and preserve the environment in line with national goals. 


\section{Acknowledgement}

The authors would like to extend their appreciation to the University Sains Malaysia for the Research University Grant entitled 'Tourism Planning' [Grant No. 1001/PTS/8660013] that makes this study and paper possible.

\section{References}

1. UNWTO (United Nations World Tourism Organization), Tourism Highlights, 2013 ed., United Nations World Tourism Organization, Madrid (2013)

2. J.A. Ibrahim, M.Z. Ahmad, Perancangan dan Pembanguna Pelancongan. Kedah: UUM Press (2012)

3. GOM (Government of Malaysia) Tenth Malaysia Plan, Government of Malaysia Printers: Kuala Lumpur (2011)

4. A. Hamzah. Policy and Planning of the Tourism Industry in Malaysia, Proceedings, The 6th ADRF General Meeting, Bangkok, Thailand, 1-21 (2004)

5. S.G. Sutton, D. Khazanchi, C. Hampton, V. Arnold V. Risk analysis in an extended enterprise environment: identification of key risk factors in B2B e-commerce relationships. J Assoc Inf Syst 9, $3,153-176(2008)$

6. C. O'hEocha, X. Wang, K..Conboy, The use of focus groups in complex and pressurised IS studies and evaluation using Klein \& Myers principles for interpretive research, Information Systems Journal: An International Journal Promoting the Study and Practice of Information Systems, 22, 3, pp. 235-256 (2012)

7. S.G. Sutton, J. Reinking, V. Arnold, On the use of grounded theory as a basis for research on strategic and emerging technologies in accounting. Journal of Emerging Technologies in Accounting (2011) 